\title{
Review of rehabilitation and habilitation strategies for children and young people with homonymous visual field loss caused by cerebral vision impairment
}

Jonathan Waddington, PhD; Timothy Hodgson, PhD

From WESC Foundation, UK; and University of Lincoln, UK.

Correspondence: Jonathan Waddington, PhD, VI Specialist Services, WESC Foundation, Topsham Road, Countess Wear, Exeter, Devon, EX2 6HA, UK. Email: jwaddington@wescfoundation.ac.uk

\begin{abstract}
Partial and homonymous visual field loss (HVFL) is a common consequence of postchiasmatic injury to the primary visual pathway or injury to the primary visual cortex. Different approaches to rehabilitation have been reported for older adults with HVFL and there is evidence to support the use of compensatory training over other proposed therapies. We reviewed the literature to investigate the current state of the art of rehabilitation and habilitation strategies for children and young people with HVFL, and whether there is enough evidence to support the use of these strategies in the paediatric population. We have provided an overview of the existing literature on children and young people with HVFL, a brief overview of rehabilitation strategies for adults with HVFL, and evidence on whether these different interventions have been applied with children and
\end{abstract}


young people effectively. We found that there have been very few studies to investigate these strategies with children and young people, and the quality of evidence is currently low. New research is required to evaluate which strategies are effective for children and young people with HVFL and whether new strategies need to be developed.

\section{Introduction and scope of review}

The visual field is the entire space that can be perceived when the eyes are fixating a target. Injury to areas of the brain involved in processing vision can result in a partial or whole loss of the visual field. If visual field loss affects both monocular visual fields in corresponding areas then there will be an overlapping area of the binocular visual field that is affected, and this is referred to as a homonymous visual field loss. Partial and homonymous visual field loss (HVFL) has a significant negative impact on independence and quality of life as daily activities such as reading, navigation, and safely avoiding obstacles are often impaired ${ }^{1,2}$.

The traditional view has been that HVFL is permanent after an acute phase when some spontaneous recovery is possible. However, this view has been challenged by research over the last two decades ${ }^{3-9}$. A number of interventions aimed at restoration of the visual field have been developed that have shown some promise in rehabilitating adults with HVFL. Although the beneficial effects of interventions are becoming established, the exact mechanism of effect for each of these different approaches remains controversial.

It is typically thought that younger people have an increased capacity for neuroplasticity and recovery from brain injury ${ }^{10,11}$. Schuett et al. ${ }^{12}$ demonstrated that HVFL rehabilitation programmes were equally effective between younger (20-34) and older (70-84) adult 
participants, but it is not clear whether this is the case for children and infants. If children do have an enhanced ability to adapt to brain injury, this leaves us with an interesting contradiction to consider. Rehabilitation programmes that are beneficial for adults with HVFL could have an improved effect for young people with HVFL. Conversely, young people with HVFL may be more likely to adapt spontaneously, such that training designed to support rehabilitation and habilitation cannot deliver further improvements.

Considerable research and advances have been made in the treatment of HVFL for older adults in recent years. However, relatively little research has focused on potential treatments for infants, children and young people. This review gives an overview of current knowledge and research into the treatment of HVFL in adults and how it may be applied to children.

The primary visual pathway and aetiology of homonymous visual field loss in children and young people

In the typically developed visual system the primary visual pathway begins with approximately $90 \%$ of retinal ganglion cells that project along the optic nerve to synapse in the lateral geniculate nucleus of the thalamus (LGN) ${ }^{13}$. Approximately half the nerve fibres projecting from each eye cross over to the opposite side of the brain at the optic chiasm, in such a way that cells corresponding to the left visual field of each eye project to the right LGN and cells corresponding to the right visual field of each eye project to the left LGN. This pattern of visual field mapping is maintained beyond the LGN within the optic radiations 
that project onto the primary visual cortex (V1), which lies predominantly within the medial occipital cerebral cortex.

Due to the pattern of visual field mapping onto its neural correlates, injury to the primary visual pathway leads to patterns of visual field loss that are predictable depending upon lesion site ${ }^{14-16}$. An injury that completely interrupts the post-geniculate primary visual pathway in the right cerebral hemisphere results in a complete left-sided homonymous hemianopia. However, hemianopia is typically complete in only $37 \%$ of cases but even incomplete homonymous hemianopia will still be congruent (affecting vision from both eyes equally) in approximately $68 \%$ of cases ${ }^{17}$. HVFL occurs within a retinotopic reference frame, such that the visual field loss moves with the eyes and corresponds to a fixed region of the retina, rather than being fixed relative to the head or body.

The most common causes of HVFL in children that have been observed are tumour (27$39 \%)$, traumatic brain injury (19-34\%), and cerebral vascular incident $(\approx 25 \%)^{18,19}$. The incidence of HVFL in children has not been investigated specifically, but can be estimated from statistics collected on the incidence of cerebral vision impairment. Cerebral vision impairment refers to a vision impairment caused by any injury to the post-geniculate primary visual pathway, primary visual cortex, or visual associative cortices. It is currently the most common cause of vision impairment in children from developed countries ${ }^{20}$. HVFL is just one potential consequence of cerebral vision impairment, but a full discussion of cerebral vision impairment and the other potential consequences is outside the scope of this review. In the United Kingdom, the cumulative incidence of cerebral vision impairment by the age of $12-16$ years has been estimated to be $0.077 \%$ ( 77 in every 100,000$)$ and is the cause of approximately $40 \%$ of all vision impairment in children ${ }^{21,22}$. Hemianopia has been 
estimated to affect $11-22 \%$ of children with cerebral vision impairment in developed countries ${ }^{23,24}$. This would indicate that the cumulative incidence of HVFL by the age of $12-$ 16 years is approximately $0.013 \%$ in the United Kingdom, affecting approximately $6 \%$ of all children with vision impairment.

Natural progression and recovery of visual function after homonymous visual field loss in children and young people

Children with acquired HVFL may recover some of their lost visual field, and in at least one case study a child has developed a complete visual field after the loss of one cerebral hemisphere ${ }^{25}$. There is also evidence that as many as $50-84 \%$ of children with a diagnosis of cerebral vision impairment will partly recover or develop some vision, with a better prognosis for those with only injury to $\mathrm{V} 1$ rather than the periventricular white matter ${ }^{26-29}$. However, detailed information on the rate and likelihood of progression and recovery of HVFL in particular is scarce, presumably due to the difficulty in performing formal visual field assessments with young children.

During typical development the effective visual field appears to rapidly increase in size between 2-6 months of age and reaches a plateau by approximately 1-2 years of age ${ }^{30}$, although the development of attention may play a role in these observed changes ${ }^{31-35}$. There is no strong evidence to suggest whether or not HVFL acquired before 1 year of age is more likely to recover during this sensitive period of visual field development. It is also well recognised that higher visual functions continue to develop after 2 years of age, in to the mid-teens ${ }^{36}$. On the one hand, HVFL acquired shortly after 2 years of age could have a greater impact on these higher visual functions because they are developing based on an 
atypical visual field. On the other hand, because this is a period of natural development, these higher visual functions may adapt to the atypical visual field in a compensatory manner and have a lesser impact on functional vision in the long term. In summary, the complex interaction between the developmental age at which brain injury occurred, the likelihood and time-course of recovery, and the long term consequences of HVFL are simply not well understood and are difficult to assess.

In contrast the natural progression of HVFL in adults has been quite well documented and may be a useful predictor for the prognosis of young people that acquire HVFL after the visual system is fully mature. It is thought that $8-20 \%$ of stroke survivors with HVFL will fully recover their visual field, although as many as $50-60 \%$ may show some spontaneous recovery of vision. Recovery of HVFL can occur within the first two days after stroke and recovery is much less likely to continue after 10-12 weeks, while complete spontaneous recovery is most likely to occur over the first 10 days ${ }^{37-39}$.

When considering the progression or recovery of HVFL it is important to distinguish between improvements in functional vision that are consciously perceived (phenomenal) and those that are not. Riddoch ${ }^{40}$ observed that motion perception may be spared (or the first perceptual function to recover) in the lost visual field, without necessarily being able to assign form or colour to the perception. Blindsight is a similar phenomenon that refers to the ability to respond to visual stimuli presented to the lost visual field but with limited conscious awareness ${ }^{41}$. A person with blindsight may be able to look or point towards a visual stimulus that they cannot necessarily perceive, and may even be able to discriminate orientation, motion or emotional expression through forced-choice guessing ${ }^{41-52}$. Unfortunately, it is not clear what proportion of people with HVFL may develop blindsight in 
their lost field. In adults, it is estimated to be anywhere between $5 \%$ and $80 \%$, depending on the parameters of the visual stimuli and the form of response tested ${ }^{52-54}$. This dependency is due to contrast sensitivity and hue discrimination in blindsight being very low outside a narrow spatial and temporal bandwidth ${ }^{46,52}$. Thus, the functional benefit of blindsight remains somewhat controversial.

There are ascending projections from subcortical areas to the visual associative cortices that bypass $\mathrm{V} 1$, and evidence suggests that these projections convey some visual signals ${ }^{55-57}$. It is therefore possible that the Riddoch phenomenon and blindsight are the result of these ascending subcortical messages being processed with limited awareness. In a relatively small study including 7 teenagers (11-17 years old), Tinelli et al. ${ }^{58}$ demonstrated that those participants with congenital HVFL showed behavioural evidence of blindsight whereas those with HVFL acquired 1-5 years after birth did not. Two of the participants with congenital HVFL underwent functional magnetic resonance imaging (fMRI) while viewing visual stimuli presented to different areas of the visual field. Interestingly, during stimulation of the lost visual field, blood oxygenation level dependent signals were detected in the ipsilateral V1 rather than in islands of remaining nervous tissue in the contralateral V1. These results may indicate that blindsight in children with congenital HVFL is dependent on profound cortical reorganisation rather than pre-existing secondary visual pathways, or potentially both conditions are necessary. visual field loss 
Alongside changes to the visual field itself, behavioural changes may develop spontaneously over time to compensate for the visual field loss. Accurate and efficient eye and head movements are a critical component of vision as they are required to move the most sensitive part of the retina (the fovea) to a position where light reflecting from the current object of interest will fall. Adults with chronic HVFL do appear to adopt different oculomotor strategies to those in the acute stage of field loss ${ }^{59}$. Additionally, Tinelli et al. ${ }^{60}$ found a greater sparing of visual search abilities in children with congenital HVFL compared to those with acquired HVFL. This indicated that children who acquire HVFL after a certain sensitive period of development may not naturally adopt optimal eye movement strategies.

One oculomotor strategy that has been suggested to partially compensate for HVFL is the development of a pseudofovea, an eccentric fixation toward the lost field so that the object of interest remains within the intact visual field ${ }^{61}$. An eccentric fixation of approximately $1^{\circ}$ has been reported in $18-28 \%$ of HVFL cases ${ }^{62,63}$. Another suggested compensatory strategy is exotropia of just the ipsilateral eye, and there have been some reported cases of HVFL patients with ipsilateral exotropia and anomalous retinal correspondence that did not result in diplopia ${ }^{64,65}$. However, strabismus is a strong risk factor for amblyopia and an adaptive ipsilateral exotropia would typically be counterproductive as the image seen through the exotropic eye could be partially suppressed due to binocular rivalry.

Gassel et al. ${ }^{66}$ and Meienberg et al. ${ }^{67}$ found that adults with HVFL would typically make multiple hypometric saccades in a staircase fashion to targets displayed $>5^{\circ}$ into the lost field. However, if the position and timing of targets remained predictable participants would learn to make an initial hypermetric saccade into the lost field followed by a backward corrective glissade to the target. As an initial hypermetric saccade brings more of the lost 
field into view, it has been suggested that this scanning strategy is more effective than the staircase strategy and could partially compensate for HVFL. Reinhard et al. ${ }^{63}$ replicated similar findings but reported no correlation between saccadic dysmetria and the length of time participants had HVFL. It remains unclear whether hypermetric scanning saccades are spontaneously adopted as a natural long-term compensatory strategy as well as a shortterm strategy in the laboratory.

A combination of head turn in the direction of the lost visual field and exotropia has been observed in children and young people with early-acquired HVFL ${ }^{68-70}$. It has been suggested that this strategy is compensatory as it could increase the functional size of the visual field by allowing larger saccades into the lost visual field. However, Mezey et al. ${ }^{71}$ found that children with chronic HVFL continue to make multiple hypometric saccades when searching for a target that is located within their lost visual field even if the eccentricity of the target is predictable, so it appears that children do not naturally adopt a hypermetric scanning strategy. However, there are other potential benefits to an ipsilateral head turn that have not been investigated such as creating a more symmetrical optic flow field during walking that could aid balance and control ${ }^{72}$. Additionally, ipsilateral head and trunk turns may modestly improve the functional visual field of patients with hemispatial neglect, which can co-occur with HVFL ${ }^{73}$.

In summary, differences in eye and head movement strategies between persons with HVFL and those without are reasonably well documented in laboratory environments. However, more detailed analysis is needed to determine which oculomotor behaviours are really adaptive, and which are maladaptive or pathological in natural scenarios. 


\section{Rehabilitation strategies for adults with homonymous visual field loss}

Rehabilitation strategies for adults with HVFL have broadly fallen into one of three categories: restitution therapy, compensatory training, and sensory supplementation.

The aim of restitution therapy is to restore or improve the remaining function in the neural correlates of the lost visual field. This is typically undertaken with visual stimulation of the lost visual field or the border between the intact and lost field using extremely bright, high contrast stimuli. Improvements in colour and simple pattern recognition have been observed using this technique ${ }^{74-79}$, although in some cases these effects appear to be mediated by blindsight rather than phenomenal vision ${ }^{80,81}$. Claims of the intervention's effectiveness at improving perimetry itself have been challenged after a study that reliably controlled for fixation during visual field assessment did not reveal any significant changes in the visual field of participants ${ }^{82}$. More recent trials have attempted to combine restitution therapy with transcranial direct current stimulation. Transcranial direct current stimulation is a non-invasive form of neurostimulation that alters cortical excitability and can promote synaptic plasticity during therapy sessions ${ }^{83-85}$. Early results have shown small but significant improvements in sensitivity and perimetry when compared with restitution therapy alone ${ }^{86,87}$.

The aim of compensatory training is to change behaviour to compensate for lost visual function. The objective is to reinforce the reciprocal connections between vision, eye movements and attention to improve the functional visual field. Training protocols vary but have typically involved either searching for a target in a complex visual scene (visual search training, VST), making repeated wide-angle saccades in the direction of the lost visual field (compensatory scanning training, CST), or reading scrolling text (reading training) ${ }^{88-93}$. 
Evidence for the effectiveness of compensatory training has been compelling with observed improvements in visual response times, reading speed, and avoiding obstacles that were significantly greater than improvements made after restitution therapy or placebo interventions ${ }^{5,8,94-98}$. However, improvements in functional vision have been shown to be task specific such that improvements made in visual search do not transfer to reading and vice versa ${ }^{99}$.

The aim of sensory supplementation is to supplement vision with a sensory substitution device or optical aid. Sensory substitution devices typically convert visual information from a wearable camera to a tactile or auditory code that can be interpreted by a vision impaired user ${ }^{100-105}$. Prisms can be affixed to spectacles to redirect visual information from the lost visual field to a place on the retina that either corresponds to the intact visual field or the border between the intact and lost visual field ${ }^{106-109}$. It is possible to expand the visual field by approximately $20^{\circ}$ using a monocular prism system, just above and just below the central vision region to avoid foveal diplopia. However, the binocular strength of the image seen through the prisms is weaker than the corresponding image seen directly through the other eye due to binocular rivalry, limiting their functional benefit ${ }^{110-112}$.

\section{Restitution therapy for children and young people with homonymous visual field loss}

It is clear that a great deal of research has been conducted into potential treatments for HVFL in adult stroke patients, and there is some evidence to indicate moderate improvements in functional vision can be made with the aid of certain rehabilitation strategies. However, there are differences in the aetiology and natural progression of HVFL 
in children when compared with adults. Additionally, children and young people are likely to require a mix of both habilitation and rehabilitation depending on the age at which brain injury occurred and the prior development of their visual and oculomotor systems. As such, it is important to assess whether rehabilitation strategies that may be effective for older adult patients with HVFL are effective for children and young people with congenital or acquired HVFL.

Werth et al. ${ }^{113}$, and Werth et al. ${ }^{114}$ investigated the effects of restitution therapy in a total of 39 children aged 1 to 15 years. The therapy involved stimulating the lost visual field with a spot of extremely bright light moving slowly along the horizontal meridian, from the periphery to the centre. Within three months 26 of the 39 children that underwent treatment had extended their visual field between $30^{\circ}$ and $90^{\circ}$, while there was no significant spontaneous recovery in a control group that underwent similar therapy but with low contrast stimuli. Importantly, for some participants improvements in the visual field perimeter extended only in areas that were stimulated during training (i.e. the horizontal meridian) and not in other areas of the lost field. Additionally, some participants did not maintain improvements in the visual field perimeter after the training period had ended but would improve again if they restarted training. $\mathrm{fMRI}$ studies on a small selection of the children that had partial visual field recovery indicated additional activity in V1 contralateral to visual field loss when compared to children who had no visual field recovery. This may indicate that these improvements were mediated by islands of spared neural tissue in the injured V1 but it is not clear whether this activity was present before training began.

It is uncommon to observe improvements on this scale in the visual field of adults undergoing restitution therapy. The difference may be due to a greater degree of plasticity 
in the infant brain, but may also be due to using a much brighter $(\times 25)$ stimulus or a difference in the aetiology of the visual field loss. Additionally, the method used to assess the visual field of the children was based on recording eye movements to targets in the periphery. As conscious awareness of targets was only assessed anecdotally, it is possible that the improvements in the visual field were due to perceptual training of blindsight without accompanying phenomenal vision. More detailed or longitudinal studies are required to assess whether the observed improvements in detection within the lost visual field of children are the result of developing phenomenal vision or blindsight after restitution therapy.

Compensatory training and sensory supplementation for children and young people with homonymous visual field loss

Studies investigating compensatory training with children and young people are not as well documented and have only recently been published. This may be partly due to children not meeting the cognitive requirements of compensatory training, as participants must be able to understand that they are being asked to find specific visual targets, hold the target in working memory, attend to a visual scene, and inhibit attention to distracting stimuli. Conversely, compensatory training is typically tiresome, uninteresting and requires weeks of commitment. As such, young people may be unwilling to participate in research to assess its effectiveness, particularly if they have congenital or early-acquired HVFL and do not have an appreciation of their own vision impairment. 
Tinelli et al. ${ }^{115}$ reported on a case series including three teenagers who had acquired HVFL in infancy. The participants trained using a specialist semicircular apparatus with mounted speakers and light emitting diodes in an audio-visual form of compensatory training (AVCT). AVCT is believed to work on the principle that multisensory neurons in the superior colliculus can integrate information from different sensory modalities, and that when sounds are played coincidentally with a visual stimulus they can improve visual perception. The aim of AVCT is to maintain these perceptual improvements after training. The three teenagers participated in daily sessions of AVCT that lasted approximately 90 minutes for 34 weeks in a sound-attenuated room. They maintained an average $36 \%$ reduction in visual response times on computer generated visual search tasks one month after training without any observed enlargement of the visual field. This is a promising result but certainly further studies including a control condition and a larger group of participants are required to corroborate the findings.

Krumm et al. ${ }^{116}$ reported on a pilot case study including a 5 year old child who had acquired a right HVFL at 2 years old. The participant's parents were asked to promote CST by providing attractions to the child's right side during playful activities. Over a period of one year the child's visual response times to targets in the lost field during table top searching tasks improved from $74 \mathrm{~s}$ to $15 \mathrm{~s}$. The authors planned to investigate whether improvements in visual response times were the result of training or developmental changes in a future study with a larger cohort of young people.

Waddington et al. ${ }^{117}$ reported on a pilot case study to evaluate the potential for using modern gaming technology to develop more engaging compensatory training programmes for children and young people. They documented the design decisions made during the 
development of a therapeutic video game for VST with two groups of young people with different presentations of neurological vision impairment, their teachers, and therapists. The searching components of the game were matched quite closely to the visual search tasks used in previous studies while the narrative progression of the game occurred between periods of visual search. Visual, auditory, and narrative feedback cues were used to keep players informed of their progression and maintain interest in the training. Three key options (the size and number of shapes presented as well as the maximum time to respond) could be adjusted after a baseline vision assessment to ensure accessibility. The game difficulty was then dynamically adjusted based on player progression to ensure an appropriate balance between accessibility and challenge over time. A clinical trial evaluating the results of playing the game for children and young people with HVFL is currently in progress.

There are no scientific or clinical studies investigating the use of prism lenses to improve visual field function for children and young people with HVFL, which is quite surprising as we are aware that prisms are fitted for older children in clinical practice. Given that evidence from studies involving adults with HVFL indicate that proper patient selection is essential for good outcomes with prism lens correction, it should also be considered essential that the effectiveness of prism lenses is assessed in children and young people.

\section{Conclusion}

In summary, a great deal of research has been conducted into the aetiology, natural progression, and potential treatment of HVFL in older adults while there are very few 
reports of similar studies in children and young people. As cerebral vision impairment is the most common form of vision impairment in children from developed countries, it is essential to evaluate how rehabilitation strategies for adults with neurological vision impairment might translate to habilitation strategies for children with similar conditions. There are clearly differences in the aetiology and natural progression of HVFL between adults and children, and likely differences between children with congenital and acquired brain injury. These differences may mean that the off-label use of rehabilitation strategies for adults to children is not appropriate, and certainly further research is required to determine which therapies may be clinically effective.

The evidence from studies involving adults with HVFL is most promising for compensatory training although there are certainly limits on the transfer of individual training effects to specific activities of daily living. With new technological developments there is also still potential for assisted restitution therapy and sensory substitution devices. Future research should focus on identifying which outcomes are associated with specific training schemes and their neurological mechanism of effect, so that design choices during the development of (re)habilitation packages can be well informed. Additionally, valid outcome measures for activities of daily living and quality of life should be identified and standardised to improve the quality of future studies and allow comparisons between them. This will enable researchers and clinicians to evaluate and select the most appropriate therapy for children and young people with HVFL, and potentially other conditions related to cerebral vision impairment.

\section{Acknowledgements}


This work was supported by the WESC Foundation, the Technology Strategy Board (now Innovate UK), and the Medical Research Council of the United Kingdom, as part of a Knowledge Transfer Partnership (Ref: KTP008989).

\section{Method of literature search}

The literature search was performed in April 2016 using the EBSCOhost online research database. The following MeSH headings were used: "(homonymous) hemianop(s)ia", "visual field loss", quadrantanopia in combination with: children, infants, "young people", "young adults", and: rehabilitation, habilitation, therapy, training. Titles and abstracts were reviewed by one researcher for relevance. Those articles that were published in English and described HVFL in young people were read in full. Due to the relatively small number of initial articles that were deemed relevant, the reference lists from the read articles were also reviewed to identify further articles of relevance to the topic. Additional articles were suggested during the peer-review process.

\section{References}

1. Warren M. Pilot study on activities of daily living limitations in adults with hemianopsia. Am J Occup Ther. 2009;63(5):626-633.

2. Hepworth L, Rowe FJ. Visual impairment following stroke - the impact on quality of life: a systematic review. Ophthalmology Res Int J. 2016;5(2):1-15.

3. Kerkhoff G. Neurovisual rehabilitation: recent developments and future directions. J Neurol Neurosurg Psychiatry. 2000;68(6):691-706. 
4. Pambakian A, Currie J, Kennard C. Rehabilitation strategies for patients with homonymous visual field defects. J Neuroophthalmol. 2005;25(2):136-142.

5. Bouwmeester L, Heutink J, Lucas $C$. The effect of visual training for patients with visual field defects due to brain damage: a systematic review. J Neurol Neurosurg Psychiatry. 2007;78(6):555-564.

6. Pelak VS, Dubin M, Whitney E. Homonymous hemianopia: a critical analysis of optical devices, compensatory training, and NovaVision. Curr Treat Options Neurol. 2007;9(1):41-47.

7. Lane AR, Smith DT, Schenk T. Clinical treatment options for patients with homonymous visual field defects. Clin Ophthalmol. 2008;2(1):93.

8. Pollock A, Hazelton C, Henderson CA, Angilley J, Dhillon B, Langhorne P, Livingstone K, Munro FA, Orr H, Rowe FJ, Shahani U. Interventions for visual field defects in patients with stroke. Cochrane Database Syst Rev. 2011;2011(10):1-86.

9. Trauzettel-Klosinski S. Current methods of visual rehabilitation. Dtsch Arztebl Int. 2011;108(51-52):871-878.

10. Kennard MA. Age and other factors in motor recovery from precentral lesions in monkeys. Am J Physiol. 1936;115:138-146.

11. Teuber HL. Functional recovery after lesions of the nervous system. II. Recovery of function after lesions of the central nervous system: history and prospects. Neurosci Res Program Bull. 1974;12(2):197-211.

12. Schuett S, Zihl J. Does age matter? Age and rehabilitation of visual field disorders after brain injury. Cortex. 2013;49(4):1001-1012.

13. Perry $\mathrm{VH}$, Oehler R, Cowey A. Retinal ganglion cells that project to the dorsal lateral geniculate nucleus in the macaque monkey. Neuroscience. 1984;12(4):1101-1123. 
14. Inouye T. Visual disturbances following gunshot wounds of the cortical visual area: based on observations of the wounded in the recent Japanese wars. (Glickstein M, Fahle M, trans). Oxford, UK: Oxford University Press; 2000.

15. Holmes G, Lister WT. Disturbances of vision from cerebral lesions, with special reference to the cortical representation of the macula. Brain. 1916;39(1-2):34-73.

16. Horton JC, Hoyt WF. The representation of the visual field in human striate cortex. A revision of the classic Holmes map. Arch Ophthalmol. 1991;109(6):816-824.

17. Kedar S, Zhang X, Lynn MJ, Newman NJ, Biousse V. Congruency in homonymous hemianopia. Am J Ophthalmol. 2007;143(5):772-780.

18. Liu GT, Galetta SL. Homonymous hemifield loss in childhood. Neurology. 1997;49(6):1748-1749.

19. Kedar S, Zhang X, Lynn MJ, Newman NJ, Biousse V. Pediatric homonymous hemianopia. J AAPOS. 2006;10(3):249-252.

20. Kong, L., Fry, M., Al-Samarraie, M., Gilbert, C., Steinkuller, P. An update on progress and the changing epidemiology of causes of childhood blindness worldwide. $J$ AAPOS. 2012;16(6):501-507.

21. Rahi, J., and Cable, N. Severe visual impairment and blindness in children in the UK. Lancet. 2003;362(9393):1359-1365.

22. Bodeau-Livinec, F., Surman, G., Kaminski, M., Wilkinson, A., Ancel, P-Y., Kurinczuk, J. Recent trends in visual impairment and blindness in the UK. Arch Dis Child. 2007;92(12):1099-1104.

23. Huo, R., Burden, S., Hoyt, C., Good, W. Chronic cortical visual impairment in children: aetiology, prognosis, and associated neurological deficits. Br J Ophthalmol. 1999;83(6):670-675. 
24. Bosch, D., Boonstra, F., Willemsen, M., Cremers, F., de Vries, B. Low vision due to cerebral visual impairment: differentiating between acquired and genetic causes. BMC Ophthalmol. 2014;14:59.

25. Werth R. Visual functions without the occipital lobe or after cerebral hemispherectomy in infancy. Eur J Neurosci. 2006;24(10):2932-2944.

26. Roland EH, Jan JE, Hill A, Wong PK. Cortical visual impairment following birth asphyxia. Pediatr Neurol. 1986;2(3):133-137.

27. Casteels I, Demaerel P, Spileers W, Lagae L, Missotten L, Casaer P. Cortical visual impairment following perinatal hypoxia: clinicoradiologic correlation using magnetic resonance imaging. J Pediatr Ophthalmol Strabismus. 1997;34(5):297-305.

28. Huo R, Burden SK, Hoyt CS, Good WV. Chronic cortical visual impairment in children: aetiology, prognosis, and associated neurological deficits. Br J Ophthalmol. 1999;83(6):670-675.

29. Hoyt CS. Visual function in the brain-damaged child. Eye (Lond). 2003;17(3):371-386.

30. Dobson, V., Brown, A., Harvey, E., Narter D. Visual field extent in children 3.5-30 months of age tested with a double-arc LED perimeter. Vision Res. 1998;38:27432760.

31. Harris, P., MacFarlane, A. The growth of the effective visual field from birth to seven weeks. J Exp Child Psychol. 1974;18(2):340-348.

32. Atkinson, J., Hood, B., Wattam-Bell, J., Braddick, O. Changes in infants' ability to switch visual attention in the first three months of life. Perception. 1992;21(5):643653.

33. Lewis, T., Maurer, D. The development of the temporal and nasal visual fields during infancy. Vision Res. 1992;32(5):903-911. 
34. Tschopp, C., Safran, A., Viviani, P., Reicherts, M., Bullinger, A., Mermoud, C. Automated visual field examination in children aged 5-8 years. Part II: Normative values. Vision Res. 1998;38:2211-2218.

35. Hunnius, S. The early development of visual attention and its implications for social and cognitive development. Prog Brain Res. 2007;164:187-209.

36. Leat, S., Yadav, N., Irving, E. Development of visual acuity and contrast sensitivity in children. J Optom. 2009;2(1):19-26.

37. Gray CS, French JM, Bates D, Cartlidge NE, Venables GS, James OF. Recovery of visual fields in acute stroke: homonymous hemianopia associated with adverse prognosis. Age Ageing. 1989;18(6):419-421.

38. Zhang X, Kedar S, Lynn MJ, Newman NJ, Biousse V. Natural history of homonymous hemianopia. Neurology. 2006;66(6):901-905.

39. Rowe FJ, Wright D, Brand D, Jackson C, Harrison S, Maan T, Scott C, Vogwell L, Peel S, Akerman N, Dodridge C, Howard C, Shipman T, Sperring U, Macdiarmid S, Freeman C. A prospective profile of visual field loss following stroke: prevalence, type, rehabilitation, and outcome. Biomed Res Int. 2013;2013:1-12.

40. Riddoch G. Dissociation of visual perceptions due to occipital injuries, with especial reference to appreciation of movement. Brain. 1917;40(1):15-57.

41. Weiskrantz L, Warrington EK, Sanders MD, Marshall J. Visual capacity in the hemianopic field following a restricted occipital ablation. Brain. 1974;97(4):709-728.

42. Pöppel E, Held R, Frost D. Residual visual function after brain wounds involving the central visual pathways in man. Nature. 1973;243(5405):295-296.

43. Sanders MD, Warrington EK, Marshall J, Wieskrantz L. "Blindsight": Vision in a field defect. Lancet. 1974;1(7860):707-708. 
44. Barbur JL, Ruddock KH, Waterfield VA. Human visual responses in the absence of the geniculo-calcarine projection. Brain. 1980;103(4):905-928.

45. Zihl J, Werth R. Contributions to the study of "Blindsight"-I. Can stray light account for saccadic localization in patients with postgeniculate field defects? Neuropsychologia. 1984;22(1):1-11.

46. Stoerig P, Cowey A. Wavelength discrimination in blindsight. Brain. 1992;115(2):425444.

47. Morland $\mathrm{AB}$, Ogilvie JA, Ruddock $\mathrm{KH}$, Wright JR. Orientation discrimination is impaired in the absence of the striate cortical contribution to human vision. Proc Biol Sci. 1996;263(1370):633-640.

48. Marcel AJ. Blindsight and shape perception: deficit of visual consciousness or of visual function? Brain. 1998;121(8):1565-1588.

49. de Gelder B, Vroomen J, Pourtois G, Weiskrantz L. Non-conscious recognition of affect in the absence of striate cortex. Neuroreport. 1999;10(18):3759-3763.

50. Danckert J, Revol P, Pisella L, Krolak-Salmon P, Vighetto A, Goodale MA, Rossetti Y. Measuring unconscious actions in action-blindsight: exploring the kinematics of pointing movements to targets in the blind field of two patients with cortical hemianopia. Neuropsychologia. 2003;41(8):1068-1081.

51. Hamm AO, Weike Al, Schupp HT, Treig T, Dressel A, Kessler C. Affective blindsight: intact fear conditioning to a visual cue in a cortically blind patient. Brain. $2003 ; 126(2): 267-275$.

52. Sahraie A, Trevethan CT, Weiskrantz L, Olson J, MacLeod MJ, Murray AD, Dijkhuizen RS, Counsell C, Coleman R. Spatial channels of visual processing in cortical blindness. Eur J Neurosci. 2003;18(5):1189-1196. 
53. Marzi CA, Tassinari G, Aglioti S, Lutzemberger L. Spatial summation across the vertical meridian in hemianopics: a test of blindsight. Neuropsychologia. 1986;24(6):749-758.

54. Stoerig P. Chromaticity and achromaticity. Evidence for a functional differentiation in visual field defects. Brain. 1987;110(4):869-886.

55. Berman RA, Wurtz RH. Exploring the pulvinar path to visual cortex. Prog Brain Res. 2008;171:467-473.

56. Berman RA, Wurtz RH. Signals conveyed in the pulvinar pathway from superior colliculus to cortical area MT. J Neurosci. 2011;31(2):373-384.

57. Schmid MC, Mrowka SW, Turchi J, Saunders RC, Wilke M, Peters AJ, Ye FQ, Leopold DA. Blindsight depends on the lateral geniculate nucleus. Nature. 2010;466(7304):373-377.

58. Tinelli F, Cicchini GM, Arrighi R, Tosetti M, Cioni G, Morrone MC. Blindsight in children with congenital and acquired cerebral lesions. Cortex. 2013;49(6):16361647.

59. Pambakian AL, Wooding DS, Patel N, Morland AB, Kennard C, Mannan SK. Scanning the visual world: a study of patients with homonymous hemianopia. J Neurol Neurosurg Psychiatry. 2000;69(6):751-759.

60. Tinelli F, Guzzetta A, Bertini C, Ricci D, Mercuri E, Ladavas E, Cioni G. Greater sparing of visual search abilities in children after congenital rather than acquired focal brain damage. Neurorehabil Neural Repair. 2011;25(8):721-728.

61. Fuchs W. Eine Pseudofovea bei Hemianopikern. Psychol Forsch. 1922;1(1):157-186. 
62. Trauzettel-Klosinski S. Eccentric fixation with hemianopic field defects: A valuable strategy to improve reading ability and an indication of cortical plasticity. Neuroophthalmology. 1997;18(3):117-131.

63. Reinhard JI, Damm I, Ivanov IV, Trauzettel-Klosinski S. Eye movements during saccadic and fixation tasks in patients with homonymous hemianopia. $J$ Neuroophthalmol. 2014;34(4):354-361.

64. Herzau V, Bleher I, Joos-Kratsch E. Infantile exotropia with homonymous hemianopia: a rare contraindication for strabismus surgery. Graefes Arch Clin Exp Ophthalmol. 1988;226(2):148-149.

65. van Waveren $M$, Jagle $H$, Besch D. Management of strabismus with hemianopic visual field defects. Graefes Arch Clin Exp Ophthalmol. 2013;251(2):575-584.

66. Gassel MM, Williams D. Visual function in patients with homonymous hemianopial II. Oculomotor mechanisms. Brain. 1963;86:1-36.

67. Meienberg O, Zangemeister WH, Rosenberg M, Hoyt WF, Stark L. Saccadic eye movement strategies in patients with homonymous hemianopia. Ann Neurol. 1981;9(6):537-544.

68. Paysse EA, Coats DK. Anomalous head posture with early-onset homonymous hemianopia. J AAPOS. 1997;1(4):209-213.

69. Donahue S, Haun A. Exotropia and face turn in children with homonymous hemianopia. J Neuro Ophthalmol. 2007;27(4):304-307.

70. Koenraads $Y$, van der Linden D, van Schooneveld M, Imhof S, Gosselaar P, Porro G, Braun K. Visual function and compensatory mechanisms for hemianopia after hemispherectomy in children. Epilepsia. 2014;55(6):909-917. 
71. Mezey L, Harris C, Shawkat F, Timms C, Kriss A, West P, Taylor D. Saccadic strategies in children with hemianopia. Dev Med Child Neurol. 1998;40(9):626-630.

72. Coats D, Paysse E. Saccadic strategies in children with hemianopia. Dev Med Child Neurol. 1999;41(6):429.

73. Parton A, Malhotra P, Husain M. Hemispatial neglect. J Neurol Neurosurg Psychiatry. 2004;75(1):13-21.

74. Zihl J, von Cramon D. Restitution of visual function in patients with cerebral blindness. J Neurol Neurosurg Psychiatry. 1979;42(4):312-322.

75. Zihl J, von Cramon D. Visual field recovery from scotoma in patients with postgeniculate damage. A review of 55 cases. Brain. 1985;108(2):335-365.

76. Kasten E, Sabel BA. Visual field enlargement after computer training in braindamaged patients with homonymous deficits: an open pilot trial. Restor Neurol Neurosci. 1995;8(3):113-127.

77. Kasten E, Strasburger H, Sabel BA. Programs for diagnosis and therapy of visual field deficits in vision rehabilitation. Spat Vis. 1997;10(4):499-503.

78. Kasten E, Poggel DA, Sabel BA. Computer-based training of stimulus detection improves color and simple pattern recognition in the defective field of hemianopic subjects. J Cogn Neurosci. 2000;12(6):1001-1012.

79. Kasten E, Wust S, Behrens-Baumann W, Sabel BA. Computer-based training for the treatment of partial blindness. Nat Med. 1998;4(9):1083-1087.

80. Sahraie A, Trevethan CT, MacLeod MJ, Murray AD, Olson JA, Weiskrantz L. Increased sensitivity after repeated stimulation of residual spatial channels in blindsight. Proc Natl Acad Sci U S A. 2006;103(40):14971-14976. 
81. Sahraie A, Macleod MJ, Trevethan CT, Robson SE, Olson JA, Callaghan P, Yip B. Improved detection following Neuro-Eye Therapy in patients with post-geniculate brain damage. Exp Brain Res. 2010;206(1):25-34.

82. Reinhard J, Schreiber A, Schiefer U, Kasten E, Sabel BA, Kenkel S, Vonthein R, Trauzettel-Klosinski S. Does visual restitution training change absolute homonymous visual field defects? A fundus controlled study. Br J Ophthalmol. 2005;89(1):30-35.

83. Liebetanz D, Nitsche MA, Tergau F, Paulus W. Pharmacological approach to the mechanisms of transcranial DC-stimulation-induced after-effects of human motor cortex excitability. Brain. 2002;125(10):2238-2247.

84. Boggio PS, Nunes A, Rigonatti SP, Nitsche MA, Pascual-Leone A, Fregni F. Repeated sessions of noninvasive brain DC stimulation is associated with motor function improvement in stroke patients. Restor Neurol Neurosci. 2007;25(2):123-129.

85. Nitsche MA, Paulus W. Sustained excitability elevations induced by transcranial DC motor cortex stimulation in humans. Neurology. 2001;57(10):1899-1901.

86. Halko MA, Datta A, Plow EB, Scaturro J, Bikson M, Merabet LB. Neuroplastic changes following rehabilitative training correlate with regional electrical field induced with tDCS. Neuroimage. 2011;57(3):885-891.

87. Plow EB, Obretenova SN, Jackson ML, Merabet LB. Temporal profile of functional visual rehabilitative outcomes modulated by transcranial direct current stimulation. Neuromodulation. 2012;15(4):367-373.

88. Zihl J. Visual scanning behavior in patients with homonymous hemianopia. Neuropsychologia. 1995;33(3):287-303. 
89. Nelles G, Esser J, Eckstein A, Tiede A, Gerhard H, Diener H. Compensatory visual field training for patients with hemianopia after stroke. Neurosci Lett. 2001;306(3):189192.

90. Pambakian AL, Mannan SK, Hodgson TL, Kennard C. Saccadic visual search training: a treatment for patients with homonymous hemianopia. J Neurol Neurosurg Psychiatry. 2004;75(10):1443-1448.

91. Ong YH, Jacquin-Courtois S, Gorgoraptis N, Bays PM, Husain M, Leff AP. Eye-Search: a web-based therapy that improves visual search in hemianopia. Ann Clin Transl Neurol. 2015;2(1):74-78.

92. Spitzyna GA, Wise RJ, McDonald SA, Plant GT, Kidd D, Crewes H, Leff AP. Optokinetic therapy improves text reading in patients with hemianopic alexia: a controlled trial. Neurology. 2007;68(22):1922-1930.

93. Ong YH, Brown MM, Robinson P, Plant GT, Husain M, Leff AP. Read-Right: a "web app" that improves reading speeds in patients with hemianopia. J Neurol. 2012;259(12):2611-2615.

94. Roth $\mathrm{T}$, Sokolov A, Messias A, Roth P, Weller M, Trauzettel-Klosinski S. Comparing explorative saccade and flicker training in hemianopia: a randomized controlled study. Neurology. 2009;72(4):324-331.

95. Lane AR, Smith DT, Ellison A, Schenk T. Visual exploration training is no better than attention training for treating hemianopia. Brain. 2010;133(6):1717-1728.

96. Mödden C, Behrens M, Damke I, Eilers N, Kastrup A, Hildebrandt H. A randomized controlled trial comparing 2 interventions for visual field loss with standard occupational therapy during inpatient stroke rehabilitation. Neurorehabil Neural Repair. 2012;26(5):463-469. 
97. Aimola L, Lane AR, Smith DT, Kerkhoff G, Ford GA, Schenk T. Efficacy and feasibility of home-based training for individuals with homonymous visual field defects. Neurorehabil Neural Repair. 2014;28(3):207-218.

98. de Haan GA, Melis-Dankers BJ, Brouwer WH, Tucha O, Heutink J. The effects of compensatory scanning training on mobility in patients with homonymous visual field defects: a randomized controlled trial. PLoS One. 2015;10(8):e0134459.

99. Schuett S, Heywood CA, Kentridge RW, Dauner R, Zihl J. Rehabilitation of reading and visual exploration in visual field disorders: transfer or specificity? Brain. 2012;135(3):912-921.

100. Bach-y-Rita P, Collins CC, Saunders FA, White B, Scadden L. Vision substitution by tactile image projection. Nature. 1969;221(5184):963-964.

101. Danilov $\mathrm{Y}$, Tyler M. Brainport: an alternative input to the brain. J Integr Neurosci. 2005;4(4):537-550.

102. Meijer PB. An experimental system for auditory image representations. IEEE Trans Biomed Eng. 1992;39(2):112-121.

103. Stronks HC, Nau AC, Ibbotson MR, Barnes N. The role of visual deprivation and experience on the performance of sensory substitution devices. Brain Res. 2015.

104. Poirier C, De Volder AG, Scheiber C. What neuroimaging tells us about sensory substitution. Neurosci Biobehav Rev. 2007;31(7):1064-1070.

105. Ward J, Wright T. Sensory substitution as an artificially acquired synaesthesia. Neurosci Biobehav Rev. 2014;41:26-35.

106. Rossi PW, Kheyfets S, Reding MJ. Fresnel prisms improve visual perception in stroke patients with homonymous hemianopia or unilateral visual neglect. Neurology. 1990;40(10):1597-1599. 
107. Peli E. Field expansion for homonymous hemianopia by optically induced peripheral exotropia. Optom Vis Sci. 2000;77(9):453-464.

108. Bowers AR, Keeney K, Peli E. Community-based trial of a peripheral prism visual field expansion device for hemianopia. Arch Ophthalmol. 2008;126(5):657-664.

109. Bowers AR, Keeney K, Peli E. Randomized crossover clinical trial of real and sham peripheral prism glasses for hemianopia. JAMA Ophthalmol. 2014;132(2):214-222.

110. Ross NC, Bowers AR, Peli E. Peripheral prism glasses: effects of dominance, suppression, and background. Optom Vis Sci. 2012;89(9):1343-1352.

111. Haun AM, Peli E. Binocular rivalry with peripheral prisms used for hemianopia rehabilitation. Ophthalmic Physiol Opt. 2014;34(5):573-579.

112. Shen J, Peli E, Bowers AR. Peripheral prism glasses: effects of moving and stationary backgrounds. Optom Vis Sci. 2015;92(4):412-420.

113. Werth $\mathrm{R}$, Moehrenschlager $\mathrm{M}$. The development of visual functions in cerebrally blind children during a systematic visual field training. Restor Neurol Neurosci. $1999 ; 15(2-3): 229-241$.

114. Werth R, Seelos K. Restitution of visual functions in cerebrally blind children. Neuropsychologia. 2005;43(14):2011-2023.

115. Tinelli F, Purpura G, Cioni G. Audio-visual stimulation improves visual search abilities in hemianopia due to childhood acquired brain lesions. Multisensory Research. 2015;28(1-2):153-171.

116. Krumm A, Staudt M, Company M, Ivanov I, Küster A, Trauzettel-Klosinski S. Explorative saccade training for children with homonymous hemianopia: case report and presentation of a planned study. Neuropediatrics. 2015;46(S 01):PS01-01. 
117. Waddington J, Linehan C, Gerling K, Hicks K, Hodgson TL. Participatory design of therapeutic video games for young people with neurological vision impairment. In: Proceedings of the 33rd Annual ACM Conference on Human Factors in Computing Systems (CHI '15). New York, USA: ACM; 2015:3533-3542. 